\title{
Physical Restraint
}

National Cancer Institute

\section{Source}

National Cancer Institute. Physical Restraint. NCI Thesaurus. Code C158344.

A material item that is placed on the body in order to restrict movement. 